\title{
Daptomycin, a last-resort antibiotic, binds ribosomal protein S19 in humans
}

\author{
Michael P. Gotsbacher ${ }^{1,{ }^{\dagger}}$, Sungmin $\mathrm{Cho}^{2 \dagger}$, Ho Jeong Kwon ${ }^{2^{*}}$ and Peter Karuso ${ }^{1^{*}}$ (D)
}

\begin{abstract}
Background: Daptomycin is a recently introduced, last-resort antibiotic that displays a unique mode of action against Gram-positive bacteria that is not fully understood. Several bacterial targets have been proposed but no human binding partner is known.

Methods: In the present study we tested daptomycin in cell viability and proliferation assays against six human cell lines, describe the synthesis of biotinylated and fluorescently labeled analogues of daptomycin. Biotinylated daptomycin was used as bait to isolate the human binding partner by the application of reverse chemical proteomics using $T 7$ phage display of five human tumor cDNA libraries. The interaction between the rescued protein and daptomycin was validated via siRNA knockdown, DARTS assay and immunocytochemistry.
\end{abstract}

Results: We have found that daptomycin possesses selective growth inhibition of some cancer cell lines, especially MCF7. The unbiased interrogation of human CDNA libraries, displayed on bacteriophage T7, revealed a single human target of daptomycin; ribosomal protein S19. Using a drug affinity responsive target stability (DARTS) assay in vitro, we show that daptomycin stabilizes RPS19 toward pronase. Fluorescently labeled daptomycin stained specific structures in HeLa cells and co-localized with a RPS19 antibody.

Conclusion: This study provides, for the first time, a human protein target of daptomycin and identifies RPS19 as a possible anticancer drug target for the development of new pharmacological applications and research.

Keywords: Daptomycin, Reverse chemical proteomics, Phage display, DARTS

\section{Background}

Daptomycin (DAP; Scheme 1) is a natural product (nonribosomal peptide) from the soil actinobacterium Streptomyces roseosporus and comprises a 10 amino acid residue macrolactone (including $3 \mathrm{D}$-amino acids) with three exocyclic amino acids linked to a fatty acid [1]. DAP has recently been introduced as a last-resort antibiotic with excellent activity against Gram-positive pathogens. It was first approved by the Food and Drug Administration (FDA) for non-topical use in 2003 for the treatment of skin infections caused by Gram-positive bacteria, and in 2006

\footnotetext{
*Correspondence: kwonhj@yonsei.ac.kr; peter.karuso@mq.edu.au Michael P. Gotsbacher and Sungmin Cho are co-first authors.

Ho Jeong Kwon and Peter Karuso are co-corresponding authors. ${ }^{\dagger}$ Equal contributors

2Department of Biotechnology, Yonsei University, 50 Yonsei-ro, Seodaemun-gu, Seoul 120-749, South Korea

'Department of Chemistry and Biomolecular Sciences, Macquarie University, Sydney, NSW 2109, Australia

Full list of author information is available at the end of the article
}

for non-topical treatment of bacteremia and right-side endocarditis caused by Staphylococcus aureus, including MRSA [2]. Despite its clinical importance, the mode of action (MOA) is still unclear, but believed to be a unique mechanism and calcium dependent [3]. Several models have been proposed to explain its antibacterial activity, including: Perturbation of the cell membrane through pore formation, membrane depolarisation or potassium efflux [4-6]; inhibition of the biosynthesis of lipoteichoic acid [7-9]; inhibition of cell wall biosynthesis through the twocomponent regulatory system YycFG, a membranespanning pair of sensor/histidine kinase and response regulator, that is required for viability and functions as a master regulator for cell wall metabolism [10]; and membrane deformation that attracts the conserved celldivision protein DivIVA $[11,12]$. Most recently, a comprehensive MOA study indicated that DAP does not form discrete pores or induce membrane deformations, but rather binds to fluid lipid domains in the cell envelope [3]. 

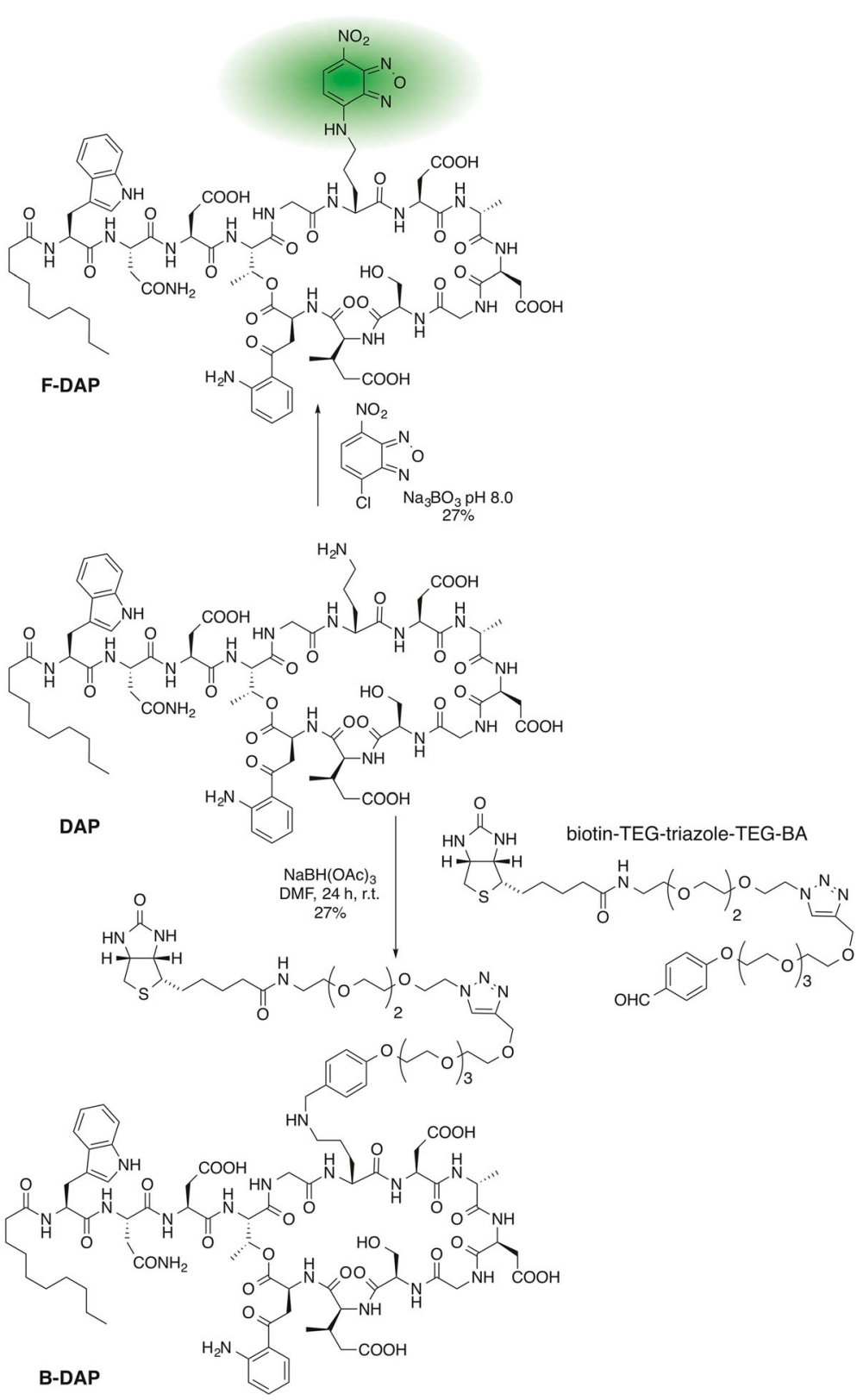

Scheme 1 Synthesis of B-DAP and F-DAP

Very little is known about its interactions of DAP with human cells, with only one reported experiment. In 1990, Canepari exposed human epithelial cells (HEp-2) to radioactively labeled DAP and observed membrane binding to occur in the presence of $\mathrm{Ca}^{2+}$ [9]. In their study DAP did not enter the cytoplasm. In addition, bound antibiotic could be removed by washing with EDTA. It was furthermore observed in phospholipid bilayer studies that DAP induces, in a $\mathrm{Ca}^{2+}$ dependent manner, substantial lipid flip-flop [5]. This phenomenon is potentially relevant for DAP's entry into human cells, but it is unknown what it interacts with in the lipid bilayer or the cytoplasm.
The side effects of clinical application of DAP $\left(\right.$ Cubicin $\left.^{\circ}\right)$ are generally non-specific, such as nausea, headache, diarrhea and vomiting [13]. However, early Phase I clinical trials showed muscle toxicity at $4 \mathrm{mg} /$ $\mathrm{kg}$ every twelve hours [14] and up to $40 \%$ of patients develop some muscle toxicity or myalgia [15]. A recent toxicity study on primary rat muscle cell cultures demonstrated that DAP has an effect on the plasma membrane of only differentiated myotubes [16]. As so little is known about the effect of DAP on human cells we initiated a chemical proteomics study to determine the human target(s) of DAP. This is important because it 
may help elucidate the mode of action underlying the observed side effects but more importantly, it has recently been recognized that bioactive small molecules often possess extensive polypharmacology across target boundaries [17-19]. Therefore, the search for the most avid human protein-binding partner may reveal possible off-label applications of DAP in humans.

Reverse chemical proteomics is the ideal tool to help elucidate targets and off-targets for this complex compound as it allows for rapid discovery of cognate drug-receptor pairs [20]. As so little is known about off-targets or other potential medical applications beyond its antibiotic capacity, we utilized a wide selection of cDNA libraries derived from both normal and diseased cells of various tissues.

\section{Methods}

\section{Synthesis of probes}

B-DAP was synthesized by reductive amination of DAP with a custom made biotinylated linker (Additional file 1: Figure S1-S6). F-DAP was synthesized by an adaptation of the method of Muraih et al. [6] (Additional file 1).

\section{Reverse chemical proteomics, target identification Reagents and materials}

The phage display protocols used were adapted from the Novagen T7 Select Manual [21]. Sodium chloride, potassium chloride, potassium dihydrogen phosphate, Tween20, IPTG, DNA molecular weight markers and carbenicillin were obtained from Sigma-Aldrich (Castle Hill, Australia). Tryptone, yeast extract, agar and polystyrene Petri dishes were obtained from Bacto Laboratories (Mt. Pritchard, Australia). Glucose, agarose, super-fine resolution agarose and Tris were purchased from AMRESCO (Solon, OH, USA). Acetic acid, glycerol, ammonium chloride, disodium hydrogen phosphate and EDTA disodium salt were obtained from $\mathrm{BDH}$ (Darmstadt, Germany). T7Select10-3 human disease cDNA libraries and E. coli strain BLT5615 were obtained from Novagen Inc. (Merck; Madison, WI, USA). Nucleotides (dNTPs) were obtained from Bioline (London, UK). Oligonucleotides (primers) were obtained from Sigma-Genosys (Castle Hill, Australia). TaqDNA polymerase and QIAquick PCR purification kits were obtained from QIAGEN (Valencia, CA, USA). HinfI restriction endonuclease and NEB buffer 2 were obtained from Promega Corp. (Madison, WI, USA). Electrophoresis grade agarose was obtained from American Bioanalytical (Natick, MA, USA). Nuclease-free water, $1 \mathrm{M}$ magnesium chloride and 20\% SDS were obtained from Ambion (Sydney, Australia). Reacti-bind HBC Neutravidin 8-well strip plates (Pierce) were obtained from ThermoFisher Scientific (Scoresby, Australia). Disposable plastic syringes were obtained from Terumo
(Tokyo, Japan). Polystyrene 96-well microtiter plates, flexible poly(vinyl chloride) 96-well assay plates and conical $250 \mathrm{~mL}$ centrifuge bottles were obtained from Corning (Corning, NY, USA). Reagents and media were prepared according to Table S1 (Additional file 1). Biosafety approval was obtained from the Macquarie University Biosafety Committee (approval number 5201000870).

\section{Equipment}

Bacterial cultures were incubated in a heated orbital shaker (Thermoline Scientific, Australia). Optical densities were recorded in $1 \mathrm{~cm}$ polystyrene semi-micro cuvettes (Sarstedt, Germany) using a BioRad SmartSpec Plus UV spectrophotometer at $600 \mathrm{~nm}$ (BioRad, USA). Solutions were centrifuged with a 6 K15 refrigerated centrifuge (Sigma, Germany). DNA was amplified with a C1000 Thermal Cycler (Bio-Rad, USA). DNA sequencing was performed by the Macquarie University DNA Analysis Facility using a 3130xl Genetic Analyzer (Applied Biosystems, USA). Agarose gel electrophoresis was performed using a Mini-Sub Cell GT system (BioRad, USA) and gels were visualized via Gel-Red stain with a G:Box Chemitransilluminator (ethidium bromide filter) using GeneSnap digital imaging software (SynGene, UK). Water was purified using a Milli-Q Ultrapure Water Purification System (Millipore, USA).

\section{Bacterial culturing}

Stocks of E. coli (strain BLT5615) were stored at $-80{ }^{\circ} \mathrm{C}$ in $10 \%$ glycerol. An initial culture was prepared by streaking a small quantity of this frozen stock onto an $\mathrm{LB}$ agar plate and incubating the plate at $37^{\circ} \mathrm{C}$ for $16 \mathrm{~h}$ and stored at $4{ }^{\circ} \mathrm{C}$ for up to 3 weeks. A saturated overnight culture of BLT5615 was prepared by inoculating M9TB $(20 \mathrm{~mL})$ with a single bacterial colony from an $\mathrm{LB}$ agar plate and then incubating at $37^{\circ} \mathrm{C}$ for $16 \mathrm{~h}$ with gentle swirling (120-150 rpm). A fresh culture of BLT5615, ready for infection by $\mathrm{T} 7$ bacteriophage, was prepared by inoculating M9TB $(100 \mathrm{~mL})$ with saturated overnight culture $(5 \mathrm{~mL})$ and incubating at $37{ }^{\circ} \mathrm{C}$ with vigorous shaking until an $\mathrm{OD}_{600}$ of 0.4 was reached (1.5-3 h). IPTG $(24 \% ; 100 \mu \mathrm{L})$ was added and incubation continued for a further $30 \mathrm{~min}$. The culture was then stored on slushy ice (for up to $24 \mathrm{~h}$ ) until required.

\section{Growth of T7 lysates}

IPTG-treated cells (100 mL, BLT5615) were infected with a T7Select cDNA library $(1 \mu \mathrm{L})$ and incubated at $37{ }^{\circ} \mathrm{C}$ with vigorous shaking until lysis had occurred (1-2 h), as indicated by a marked decrease in $\mathrm{OD}_{600}$. Immediately following lysis, the lysate was centrifuged at $4700 \mathrm{rpm}$ for $10 \mathrm{~min}$ at $4{ }^{\circ} \mathrm{C}$ to precipitate cellular debris and the supernatant was decanted into a clean tube containing Tween-20 (1\%; $1 \mathrm{~mL})$. The clarified 
lysate containing $0.01 \%$ Tween-20 was stored on slushy ice until required.

\section{Stock solutions of biotinylated natural products and controls}

Stock solution of B-DAP and B-PROP $(1 \mu \mathrm{mol} / \mathrm{mL}$ in DMSO) were stored at $-80{ }^{\circ} \mathrm{C}$. Dilutions (1:100) in PBS $(\mathrm{pH}=7.4)$ resulted in $10 \mathrm{nmol} / \mathrm{mL}$ solutions and these were stored at $-20{ }^{\circ} \mathrm{C}$ for up to two days.

\section{Biotinylated natural products on neutravidin-coated PS plates}

Neutravidin-coated strip wells (Pierce) were pre-incubated with PBS $(250 \mu \mathrm{L})$ for $1 \mathrm{~h}$ at room temperature before use. The wells were emptied and $100 \mu \mathrm{L}$ probe solutions $(10 \mathrm{nM})$ were applied for $2 \mathrm{~h}$ at room temperature. The supernatant was removed, each well washed with PBS $(3 \times 250 \mu \mathrm{L})$ and immediately used for affinity selection.

\section{Affinity selections}

Clarified T7 phage lysate $(200 \mu \mathrm{L})$ was added to one well of a neutravidin-coated PS plate that had been derivatized with a biotinylated control compound, and was left to incubate for $1 \mathrm{~h}$ at room temperature. The lysate was then transferred to a second well of the plate that had been derivatized with the biotinylated target molecule, and was left to incubate for $3 \mathrm{~h}$ at room temperature. The well was washed with PWB $(3 \times 250 \mu \mathrm{L})$ and eluted with SDS $(1 \% ; 100 \mu \mathrm{L})$ for $30 \mathrm{~min}$ at room temperature. Finally, the eluate was diluted with $2 x Y T(1: 10 ; 900 \mu \mathrm{L})$ and stored at $4{ }^{\circ} \mathrm{C}$ overnight, during which time a portion of the SDS precipitated. The following day, an aliquot of the eluate $(1: 10$ in $2 x Y T ; 20 \mu \mathrm{L})$ was removed, taking care not to disturb any precipitated SDS, and added to fresh IPTG-treated BLT5615 E. coli cells (20 mL; $\mathrm{OD}_{600}$ 0.4-0.6) for the next round of selection. This procedure was repeated until 7-12 rounds of selection had been completed. The stringency of the washing step was increased with each successive round of selection, from $3 \times 250 \mu \mathrm{L} \mathrm{PWB}$ over $10 \mathrm{~s}$ in Round 1 , to $5 \times$ $250 \mu \mathrm{L}$ PWB over $2 \mathrm{~min}$ in rounds $7-12$. PCR of the sublibraries (Additional file 1: Figure S4) was used to monitor convergence.

\section{Titring}

Standard, round, LB agar plates were pre-warmed to $37{ }^{\circ} \mathrm{C}$. LB agarose $(5 \mathrm{~mL})$ was completely melted in a microwave oven and allowed to cool to $50{ }^{\circ} \mathrm{C}$. IPTGtreated BLT5615 cells $\left(250 \mu \mathrm{L}, \mathrm{OD}_{600}=0.8-1\right)$ and IPTG $(24 \% ; 5 \mu \mathrm{L})$ were added to the cooled agarose and the mixture was poured onto one LB agar plate. To allow for the agarose to completely set, the plate was kept uncovered at room temperature for $30-45 \mathrm{~min}$. The phage eluate retained from each round of selection was serially diluted with $2 \mathrm{xYT}$ medium from $10^{-1}$ to $10^{-10}$ in a flexible 96-well assay plate. A small aliquot $(2 \mu \mathrm{L})$ of each dilution from each round of selection was dropped onto the surface of the solidified agarose using a multichannel micropipette $(8 \times 5$ array per plate). The uncovered plate was left to stand at room temperature until the drops had adsorbed entirely into the agarose. Each plate was then incubated for $2-3 \mathrm{~h}$ at $37^{\circ} \mathrm{C}$ until plaques were clearly visible against the lawn of bacteria. The phage titer was calculated from that particular phage dilution of each round of selection, which contained a countable number $(5-50)$ of plaques. The phage titers for each library from round 2 to round 9 are displayed in Additional file 1: Figure S8.

\section{Picking plaques}

Serial dilutions $\left(10^{1}-10^{-7}\right)$ with $2 \mathrm{xYT}$ were prepared from amplified phage lysate from the final round of selection. LB agarose $(5 \mathrm{~mL})$ was completely melted in a microwave oven and allowed to cool to $50{ }^{\circ} \mathrm{C}$. IPTGtreated BLT 5615 cells $\left(250 \mu \mathrm{L}, \mathrm{OD}_{600}=0.8-1\right)$, IPTG $(24 \% ; 5 \mu \mathrm{L})$ and an aliquot $(50 \mu \mathrm{L})$ of the $10^{-7}$ dilution were added to the cooled agarose and the mixture was poured onto one LB agar plate. After allowing for the agarose to completely settle, the plate was incubated at $37{ }^{\circ} \mathrm{C}$ until plaques were clearly visible against the lawn of bacteria $(2-4 \mathrm{~h})$. Individual plaques (24) were collected by stabbing the centre of each plaque with a $10 \mu \mathrm{L}$ micropipette tip and transferring the tip to IPTGtreated BLT5615 cells $\left(\mathrm{OD}_{600}=0.6-0.8 ; 100 \mu \mathrm{L}\right)$ in a 96well microtiter plate. The tips were removed and the plate was incubated until complete lysis of bacterial cells occurred in each well (1-2 h). The plate was centrifuged at $4300 \mathrm{rpm}$ for $10 \mathrm{~min}$ at $4{ }^{\circ} \mathrm{C}$. An aliquot $(40 \mu \mathrm{L})$ of the supernatant was transferred into a clean 96 -well microtiter plate containing $80 \%$ glycerol $(10 \mu \mathrm{L}$ per well $)$ and stored at $-80{ }^{\circ} \mathrm{C}$ until required.

\section{Amplification, sequencing and fingerprinting of CDNA inserts}

A solution of phage lysate $(0.5 \mu \mathrm{L})$ and PCR master mix (19.5 $\mu \mathrm{L}$, including Taq Polymerase) was prepared and subjected to 20 rounds of thermocycling using the protocol shown in Additional file 1: Table S2. An aliquot of the amplified DNA solution $(2 \mu \mathrm{L})$ was then incubated with the DNA fingerprinting mix $(4 \mu \mathrm{L})$ at $37{ }^{\circ} \mathrm{C}$ for $1 \mathrm{~h}$.

\section{Agarose gel electrophoresis}

Electrophoresis-grade agarose (0.6 g) was suspended in $1 \times$ TAE buffer $(40 \mathrm{~mL})$ and the suspension was boiled in a microwave oven until the agarose had dissolved completely. The $1.5 \%$ solution was poured into a casting tray $(10 \times 7 \mathrm{~cm})$ containing two 15 well combs, and allowed 
to set for $30-45 \mathrm{~min}$ at room temperature. Once the gel had solidified, it was transferred to a gel tank, flooded with $1 \times$ TAE, and the combs were removed. For gel electrophoresis of PCR products of single plaques picked from the final round of selection, the agarose concentration was increased to $2 \%$. All digested fingerprinting samples were run in gels made up of super-fine resolution agarose (3\%). Each amplified cDNA insert of digested fingerprinting sample $(5 \mu \mathrm{L})$ was mixed with $6 \times$ DNA loading buffer $(1 \mu \mathrm{L})$ and loaded onto the gel with a micropipette. After all samples had been loaded, the gel was run at $80 \mathrm{~V}$ until the bromophenol blue dye had migrated approximately half way down each half of the gel (25-30 $\mathrm{min})$. The gel was then removed from the tank and submerged in a Gel-Red ${ }^{\oplus}$ post-staining solution $(3.3 \times)$ for $60 \mathrm{~min}$. After de-staining in deionized water (10 min), the gel was visualized using an G:BOX Chemitransilluminator. DNA fingerprinting of random plaques was performed on all cDNA libraries.

\section{DNA sequencing}

All randomly picked plaques were examined by DNA sequencing. An aliquot of PCR-amplified DNA $(10 \mu \mathrm{L})$ was purified using a QIAquick PCR purification kit following the manufacturer's instructions, providing $30 \mu \mathrm{L}$ solution containing the purified DNA. An aliquot $(8 \mu \mathrm{L})$ was combined with one PCR primer $(1 \mu \mathrm{M}$; $4 \mu \mathrm{L}, 4 \mathrm{pmol})$ and the resulting solution was submitted for DNA sequencing.

\section{Target validation}

\section{On-phage binding study}

Twelve neutravidin-coated microtiter plate wells were preconditioned with PBS $(250 \mu \mathrm{L})$ for $1 \mathrm{~h}$ at room temperature before use. Six wells were derivatized with the B-PROP and six with B-DAP (100 $\mu \mathrm{L}, 10 \mathrm{nM} ; 2 \mathrm{~h})$. A single phage plaque expressing RPS19 (LiT C1; Additional file 1: Table S3) was reamplified in E.coli BLT5615 and the phage lysate clarified (centrifugation) and aliquots $(100 \mu \mathrm{L})$ incubated in three B-PROP and three B-DAP derivatized wells ( $2 \mathrm{~h}, \mathrm{rt}$ ). Similarly, wildtype phage (no insert) lysates were incubated in the remaining six wells. The lysates were aspirated and the wells were washed with PWB $\left(10 \times 250 \mu \mathrm{L} \times 3 \mathrm{~s} ; 4^{\circ} \mathrm{C}\right)$. Any phage particles remaining in the well were eluted with SDS $(1 \% ; 100 \mu \mathrm{L})$ over $20 \mathrm{~min}$. Serial dilutions were made from the eluates with $2 \mathrm{xYT}$ and titered (Fig. 4). Under these conditions, a background of $\sim 10^{7}$ phage particles is eluted from the strip wells except for the three wells coated with B-DAP and incubated with LiT C1 phage that expressed RPS19. In this case $10^{9}$ phage were eluted indicating that there is a specific interaction between RPS19 and DAP.

\section{Cell culture}

MCF7, Huh7, Chang, A549 and HeLa (7-10 passages) cells were cultured in Dulbecco's modified Eagle's medium (DMEM, Gibco-BRL, Grand Island, NY, USA). HCT116 (7-10 passages) cells were cultured in Roswell Park Memorial Institute medium (RPMI, Gibco-BRL, Grand Island, NY, USA). U87MG (7-10 passages) cells were cultured in Minimum Essential Medium (MEM, Gibco-BRL, Grand Island, NY, USA). All media contain $10 \%$ fetal bovine serum (FBS, Gibco-BRL) and $1 \%$ antibiotic-antimycotic (Gibco-BRL). Cells were incubated in a humidified incubator with $5 \% \mathrm{CO}_{2}$ at $37{ }^{\circ} \mathrm{C}$. Cells were harvested using TrypLE ${ }^{\mathrm{TM}}$ Express Enzyme ( $1 \mathrm{~mL} ; 1 \mathrm{~min}, \mathrm{Gibco}-\mathrm{BRL})$ and the medium lightly centrifuged $3000 \times \mathrm{g}, 1 \mathrm{~min}, 25^{\circ} \mathrm{C}$ ).

\section{Cell proliferation assay}

MCF7, HCT116, Huh7, Chang, A549, and U87MG cells $\left(3 \times 10^{3}\right)$ were seeded onto 96-well plates (Tissue Culture Testplate, transparent and flat bottom, SPL Life Science, Pocheon-si, Korea) and maintained for $24 \mathrm{~h}$ to stabilize. DAP $(0,5,10,20,40$ and $80 \mu \mathrm{M})$ was added to each well and incubated for 24, 48 and $72 \mathrm{~h}$. Cell proliferation was measured (in triplicate) using 3-(4,5-dimethylthiazol-2-yl)-2,5-diphenyltetrazolium bromide (MTT; Sigma-Aldrich) at $0.4 \mathrm{mg} / \mathrm{mL}$ (final concentration) according to previous report [22].

\section{Cell viability assay}

MCF7 cells $\left(1 \times 10^{4}\right)$ were seeded onto 24 -well plates (Tissue Culture Testplate, transparent and flat bottom, SPL Life Science, Pocheon-si, Korea) and maintained for $24 \mathrm{~h}$ to stabilize. DAP $(0,5,10,20,40$ and $80 \mu \mathrm{M})$ was added to each well and incubated for $72 \mathrm{~h}$. Cell viability was measured (in triplicate) using trypan blue stain (Life technologies, NY, USA).

\section{SDS-PAGE and Western blotting}

MCF7 cells $\left(6 \times 10^{4}\right.$ cells/well $)$ were seeded onto 12 -well plates and grown for $24 \mathrm{~h}$ in a humidified incubator with $5 \% \mathrm{CO}_{2}$ at $37{ }^{\circ} \mathrm{C}$. Cells with trypsin treated were lysed by $2 \times$ SDS sample buffer (0.12 M Tris-Cl, pH 6.8, 3.3\% SDS, $10 \%$ glycerol, 3.1\% DTT) and the lysates separated by $12.5 \sim 8 \%$ sodium dodecyl sulfate polyacrylamide gel electrophoresis (SDS-PAGE; resolving buffer 1.5 M Tris$\mathrm{Cl}$, pH 8.8, stacking buffer $0.5 \mathrm{M}$ Tris-Cl, $\mathrm{pH}$ 6.8). The running buffer was made of Tris $(3 \mathrm{~g} / \mathrm{L})$, SDS $(1 \mathrm{~g} / \mathrm{L})$ and glycine $(14.4 \mathrm{~g} / \mathrm{L})$. The gels were transferred $(2.275 \mathrm{~g} / \mathrm{L}$ Tris and $7.5 \mathrm{~g} / \mathrm{L}$ glycine) to PVDF membranes (Millipore, Billerica, MA, USA). Membranes were blocked with 3\% skim milk or $1 \%$ Bovine Serum Albumin (BSA, SigmaAldrich) incubated overnight at $4{ }^{\circ} \mathrm{C}$ with the following primary antibodies: anti-RPS19 (sc-100836, Santa Cruz Biotechnology), anti-actin (ab6276, Abcam), anti-HLA A 
(ab52922, Abcam) and Rabbit and mouse secondary antibody (1:3000 v/v, GE Healthcare, Buckinghamshire, UK) were treated in $3 \%$ skim milk or $1 \%$ BSA for $1 \mathrm{~h}$ at $25^{\circ} \mathrm{C}$. Immunolabeling was detected by an enhanced chemiluminescence (ECL) kit (GE Healthcare) according to the manufacturer's instructions and detected on a ChemiDoc XRS+ (BioRad, Hercules, CA).

\section{SIRNA}

To knockdown RPS19 mRNA, MCF7 cells $\left(6 \times 10^{4}\right.$ cells/ well) were seeded onto 12-well plates in fresh DMEM without FBS. The cells were treated with $40 \mathrm{nM}$ human RPS19 siRNA SMARTpool (L-003771-00, GE Healthcare Dharmacon, Buckinghamshire, UK), 40 nM non-targeting pool (D-001810-10, GE Healthcare Dharmacon) as control and Lipofectamine 2000 transfection reagent $(3 \mu \mathrm{L}$, Life Technologies, MA, USA). ON-TARGETplus SMARTpool siRNA consisted of 4 siRNAs all targeting human RPS19. ON-TARGETplus Non-targeting Pool siRNA consisted of 4 siRNAs (UGGUUUACAUGUCGACUAA, UGGUUUACAUGUUGUGUGA, UGGUUUACAUGUU UUCUGA, UGGUUUACAUGUUUUCCUA). After $4 \mathrm{~h}$, FBS $(10 \% \mathrm{v} / \mathrm{v}$ final) was added to the media. After $24 \mathrm{~h}$, the efficiency of siRNA knockdown was analyzed by Western blotting.

\section{DARTS}

MCF7 cells $\left(6 \times 10^{6}\right)$ were lysed by homogenising in PBS buffer treated with a protease/phosphatase inhibitor cocktail (1/2 tablet/25 mL; Pierce, Rockford. IL, USA) and the protein concentration was measured using a Bradford assay. The cell lysate (protein concentration; $1.5 \mathrm{mg} / \mathrm{mL}, 100 \mu \mathrm{L}$ ) was aliquoted into $1.5 \mathrm{~mL}$ tubes. The cell lysate was incubated at $4{ }^{\circ} \mathrm{C}$ with 0 or $100 \mu \mathrm{M}$ DAP (in $3 \mu \mathrm{L}$ DMSO) for $4 \mathrm{~h}$ with rotation and then pronase (in water) added $(0.1 \mathrm{mg} / \mathrm{mL}$ final concentration) and incubated for $0,5,10$ and $20 \mathrm{~min}$ at $25{ }^{\circ} \mathrm{C}$. Protease activity was stopped by addition of $6 \times$ SDS sample buffer to a final concentration of $1 \times$ SDS and the samples boiled for $7 \mathrm{~min}$. The protein levels of RPS19 and HLA-A were quantified by using Western blotting (see above).

\section{Immunocytochemistry}

For competition assay of DAP to F-DAP, HeLa cells $\left(1.5 \times 10^{5}\right.$ cells/well $)$ were seeded in 6 well plates with coverslips and incubated at $37{ }^{\circ} \mathrm{C}$ for $24 \mathrm{~h}$. DAP (0 or $50 \mu \mathrm{M}$ final concentration), Biotin $(50 \mu \mathrm{M})$, and Cryptopleurine $(50 \mu \mathrm{M})$ were added and incubated for $1 \mathrm{~h}$ followed by F-DAP (20 $\mu \mathrm{M}$ final concentration) for an additional $30 \mathrm{~min}$. Cells were washed $(3 \times$ DMEM) and fixed with $4 \%$ paraformaldehyde in PBS for $5 \mathrm{~min}$. Cells were analyzed by confocal microscopy (LSM700, Carl Zeiss, Oberkochen, Germany). Excitation at 405, and
$488 \mathrm{~nm}$ was used for Hoechst 33342, and F-DAP respectively with 435, and $518 \mathrm{~nm}$ emission filters for Hoechst, and F-DAP, respectively.

\section{Statistical analysis}

Linear and non-linear least squares regression analysis was performed using Prism 5.0 (GraphPad Software, USA). All quantitative results are expressed as mean \pm standard error (S.E.M) and the Student's $t$-test (GraphPad Prism) was used to determine statistical significance between two groups. A $p$-value $<0.05$ was considered statistically significant $(* p<0.05, * p<0.01)$. One-way ANOVA test (GraphPad Prism) was used to determine statistical significance for a series.

\section{Molecular modeling}

The high resolution (3.6 $\AA$ ) cyroEM structure of the human ribosome (PDB ID 5T2C) [23] was loaded into MOE2016.08 (Chemical Computing Group). RPS19 was extracted from the structure and prepared for docking by $3 \mathrm{D}$ protonation $(\mathrm{pH} 7.2,300 \mathrm{~K}, 0.1 \mathrm{M}$ salt with a dielectric of 80) and the structure relaxed, tethering all heavy atoms and allowing the hydrogens to move during minimization $(\mathrm{RMS}<0.001)$. A database of the NMR solution structures of DAP (PDB ID 1XT7, 1T5M and $1 \mathrm{~T} 5 \mathrm{~N})[5,24]$ was constructed and docked (default conditions) against the isolated RPS19. Docked structures were ranked according to their final interaction energy calculated to be the sum of the van der Waals electrostatics and solvation energies, under the Generalized Born solvation model (GB/VI).

\section{Results}

Biological activity of DAP in human cell lines

DAP was bioassayed against six human cell lines, up to $80 \mu \mathrm{M}$ for 3 days (Table 1; Additional file 1: Figure S9). No toxicity, even at the highest concentration, was observed, but there was growth inhibition of MCF7 and HCT116 cell lines. MCF7 growth rates were strongly affected even at $5 \mu \mathrm{M}$ (Fig. 1a and c). Cell viability after 3 days was confirmed using trypan blue (Fig. 1b) and the growth rate (percentage growth compared to no treatment) supported growth inhibition and not lethality.

Table 1 The effect of DAP on the proliferation of various cell lines. The normal and cancer cells were treated with DAP up to $80 \mu \mathrm{M}$. The effect of DAP on cell proliferation was measured for three days with MTT assay after drug treatment. $\mathrm{GI}_{50}$ values were calculated on sigmoidal dose-response graphs after three days by GraphPad Prism

\begin{tabular}{|c|c|c|c|c|c|c|}
\hline \multirow[b]{2}{*}{ Cell lines } & \multirow{2}{*}{$\begin{array}{l}\text { Normal cells } \\
\text { Chang }\end{array}$} & \multicolumn{5}{|c|}{ Cancer cells } \\
\hline & & MCF7 & A549 & HCT116 & U87MG & Huh7 \\
\hline $\mathrm{Gl}_{50}(\mu \mathrm{M})$ & $>100$ & 3.8 & $>100$ & 6.5 & $>100$ & $>100$ \\
\hline
\end{tabular}




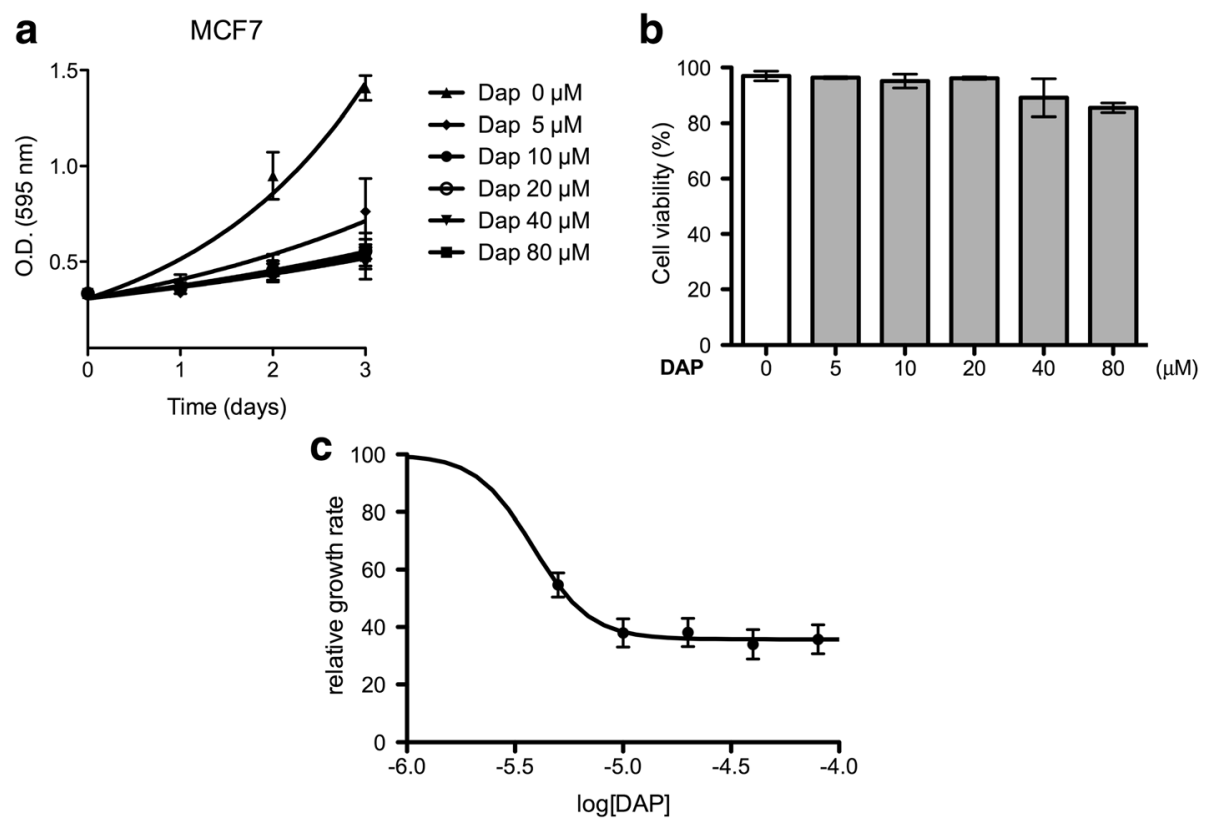

Fig. 1 The proliferation of MCF7 (breast cancer cells) was inhibited by DAP without cell toxicity. a Effect of DAP on the proliferation of MCF7 cells was measured up to 3 days. DAP was treated in triplicate at each concentration. $\mathbf{b}$ Effect of DAP on the viability of MCF7 cells was investigated by using a trypan blue staining assay $(p=0.003$, one-way ANOVA). $\mathbf{c}$ The growth rates from $(\mathbf{a})(\mathrm{t}=3 \mathrm{~d})$ plotted against log[DAP]. 100\% equal the growth rate of untreated cells

The growth inhibition for MCF7 cells was confirmed using trypan blue (Fig. 1b).

To identify the human binding partner(s) for DAP, we applied reverse chemical proteomics, using biotinylated DAP (B-DAP) as the bait and colon, liver, lung and breast tumor cDNA libraries displayed on T7-bacteriophage.

\section{Chemistry}

DAP was conjugated to a biotinylated linker, biotinTEG-triazole-TEG-BA, (Scheme 1) via a reductive amination [25]. The linker was constructed from BiotinNHS and specifically designed tetraethyleneglycol linkers (Additional file 1). A control probe (B-PRO) was synthesized using propylamine instead of DAP, with exactly the sample biotinylated linker to mimic the side chain ornithine (Additional file 1). The structure of the probes was confirmed by NMR spectroscopy and mass spectrometry (Additional file 1). Antimicrobial assay of B-DAP confirmed that the probe was still active as an antibiotic albeit, $10 \times$ less active than DAP (Additional file 1: Figure S7). Mass spectrometry revealed that BDAP contained $\sim 60 \%$ B-DAP with biotin sulfoxide. It is likely that the copper catalyzed click reaction used in constructing biotin-TEG-triazole-TEG-BA resulted in partial oxidation of biotin. However, while several oxidative side-reactions are known for this reaction [26], this is the first example of oxidation of a sulfide. The separation of those two species proved unnecessary because biotin sulfoxide also binds to neutravidin, but with a lower affinity [27], and the presence of the sulfoxide cannot affect the biopanning. In addition, use of excess probe would wash away the lower affinity biotin sulfoxide probe.

Strip wells coated with neutravidin (Pierce) were incubated with excess B-DAP or B-PRO ( $2 \mathrm{~h})$, rinsed and the $\mathrm{B}-\mathrm{PRO}$ derivatized wells incubated with the lysate from five T7 phage-displayed human cDNA libraries (normal colon, colon cancer, breast cancer, liver cancer and lung cancer) for $1 \mathrm{~h}$ and then the lysate transferred to B-DAP derivatized wells $(3 \mathrm{~h})$. The lysate was aspirated and the wells washed with buffer and the adherent phages eluted with SDS. Reapplication of the eluted phages (E. coli) produced round 1 sublibrary, which was preincubated with B-PRO coated wells and then B-DAP well, washed and eluted to produce round 2 sublibrary. This process was repeated 9-12 times to isolate the most avid binding phages from the initial cDNA libraries (Fig. 2).

The selections of random plaques from the final round of biopanning were subject to PCR amplification and HinfI fingerprinting, and separated by gel electrophoresis (Fig. 3). The HinfI digestion of the PCR products allowed fingerprinting of the rescued clones and those that appeared several times were purified and sequenced (Table 2).

The majority of clones that were in frame with the T7 bacteriophage coat protein, displayed ribosomal protein S19 (RPS19) on their surface. 

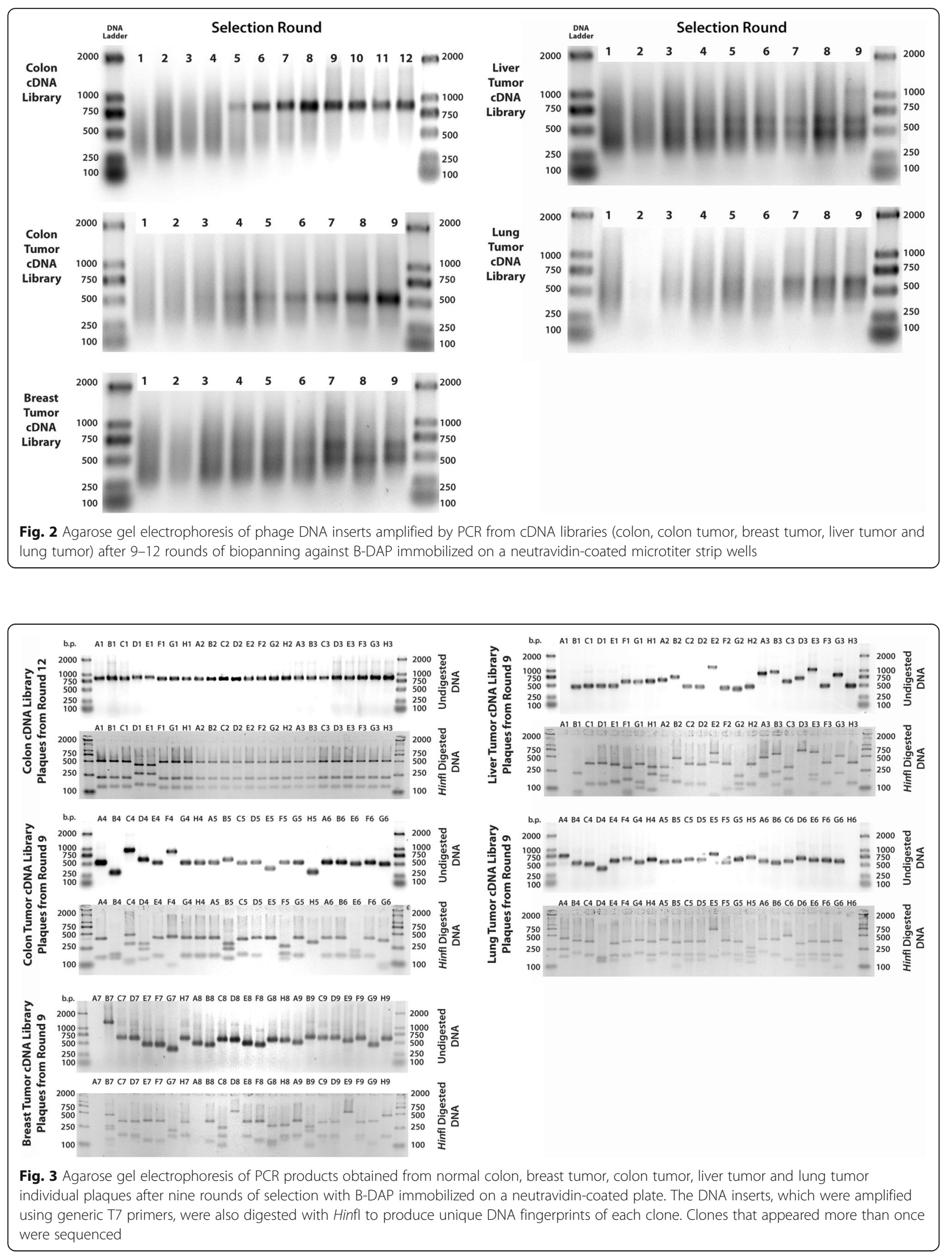
Table 2 DNA sequencing of PCR products obtained from individual plaques after nine rounds of selection with B-DAP immobilized on a neutravidin-coated PS microtiter plate. The DNA sequences of each plaque are available upon request

\begin{tabular}{|c|c|c|c|c|}
\hline Library & Plaques & Gene Identified from DNA Sequence & Notes & Frame \\
\hline $\mathrm{Col}^{\mathrm{a}}$ & A3 & leukocyte receptor cluster (LRC) member 8 & minor fraction of CDS & 1 \\
\hline $\mathrm{Col}^{\mathrm{a}}$ & D1 & tenascin C (TNC) & $500 \mathrm{bp}$ of $6400 \mathrm{bp}$ CDS & 1 \\
\hline CoT & $\mathrm{A} 4, \mathrm{E} 4, \mathrm{G} 4, \mathrm{H} 4$ & ribosomal protein S19 & $350 \mathrm{bp}$ of $420 \mathrm{bp}$ CDS & 1 \\
\hline COT & B4 & dynamin 2 (DNM2) & only late $180 \mathrm{bp}$ of $2500 \mathrm{bp}$ CDS & 2 \\
\hline CoT & B5 & sphingomyelin phosphodiesterase 4 & outside CDS & - \\
\hline LiT & $\mathrm{C} 1, \mathrm{D} 1, \mathrm{C} 2, \mathrm{H} 3$ & ribosomal protein S19 & $350 \mathrm{bp}$ of $420 \mathrm{bp}$ CDS & 1 \\
\hline LiT & E1 & ribosomal protein S19 & $360 \mathrm{bp}$ of $420 \mathrm{bp}$ CDS & 1 \\
\hline LiT & B2 & required for meiotic nuclear division 5 homolog $B$ & gene in backwards & - \\
\hline LiT & A3 & UDP-Gal:betaGlcNAc beta 1,4- galactosyltransferase, polypeptide 5 & gene in backwards & - \\
\hline LiT & B3 & RAD21 homolog (S. pombe) & $500 \mathrm{bp}$ of $1800 \mathrm{bp}$ CDS & 1 \\
\hline LuT & $\mathrm{A} 4, \mathrm{C} 5$ & ribosomal protein $\mathrm{S10}$ & last $360 \mathrm{bp}$ of $500 \mathrm{bp}$ CDS & 1 \\
\hline LuT & C4 & ribosomal protein S19 & $300 \mathrm{bp}$ of $420 \mathrm{bp}$ CDS & 1 \\
\hline $\mathrm{BrT}$ & B7 & v-erb-b2 erythroblastic leukemia viral oncogene homolog 2, neuro & very late $480 \mathrm{bp}$ of $3680 \mathrm{bp}$ CDS & 1 \\
\hline $\mathrm{BrT}$ & D7 & ribosomal protein S19 & $300 \mathrm{bp}$ of $420 \mathrm{bp}$ CDS & 1 \\
\hline $\mathrm{BrT}$ & A9 & ribosomal protein S19 & $330 \mathrm{bp}$ of $420 \mathrm{bp}$ CDS & 1 \\
\hline BrT & D9 & ribosomal protein $\mathrm{S} 10$ & $430 \mathrm{bp}$ of $500 \mathrm{bp}$ CDS & 1 \\
\hline $\mathrm{BrT}$ & E9 & BAC clone RP11-22 K23 & outside CDS & - \\
\hline $\mathrm{BrT}$ & $\mathrm{H} 9$ & LYR motif containing 5 & $230 \mathrm{bp}$ of $270 \mathrm{bp}$ CDS & 1 \\
\hline
\end{tabular}

${ }^{a}$ Plaques derived from this library were picked after 12 rounds of selection

\section{Target validation}

Initially, an on-phage binding assay was performed to determine if the T7 phage displaying RPS19 clones (clone C1 from the liver tumor cDNA library) had greater affinity for neutravidin-coated plates derivatized with B-DAP than for similar plates derivatized the control (B-PRO). A T7 clone with no cDNA insert, was used as a negative control. The assay was conducted in triplicate and the results show a statistically significant ( $p<0.001$, one-way ANOVA) higher binding to DAP derivatized plates (Fig. 4).

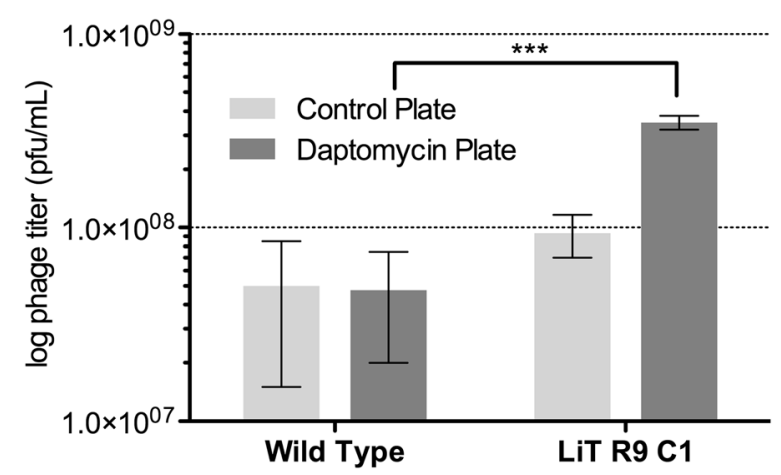

Fig. 4 On-phage binding study comparing the affinity of the RPS19displaying phage clone C1 (from liver tumor sublibrary of round-9) for neutravidin-coated plates derivatized with a control compound and a similar plate derivatized with B-DAP
Drug affinity responsive target stability (DARTS) [28] was used to validate the direct binding of DAP to RPS19 in vitro. With $0.1 \mathrm{mg} / \mathrm{mL}$ of pronase for $5 \mathrm{~min}$ there was a significant ( $p=0.0478$, Students $t$-test) protection from hydrolysis of RPS19 in MCF7 whole cell lysate in the presence of $100 \mu \mathrm{M}$ DAP (Fig. 5). In contrast HLA-A was degraded constantly irrespective of the presence of DAP. The binding of DAP to RPS19 was further investigated in HeLa cells through confocal microscopy. In order to visually confirm the binding of DAP to RPS19, F-DAP was synthesized and used in a competitive binding study. Cells that were pretreated with unlabeled DAP and then stained with F-DAP (Fig. 6, panel 3), showing little or no staining. In contrast, pretreatment of cryptopleurine (CRY) and biotin did not compete with F-DAP staining, demonstrating that F-DAP and unlabeled DAP share the same binding protein and site of the protein in the cytosol of HeLa cells (Fig. 6). F-DAP and RPS19Ab were also found to partially colocalize in the cytosol of HeLa cells where RPS19 is mainly localized (Fig. 7), suggesting that F-DAP and DAP bind to RPS19 in living cells.

The effect of knocking down RPS19 on the proliferation of MCF7 cells was investigated using siRNA (Fig. 8a-c). Treatment of MCF7 cells with 40 nM siRNA against RPS19 (siRPS19) or random siRNA (Fig. 8a), resulted in a 50\% reduction in RPS19 levels $(p=0.024)$ 


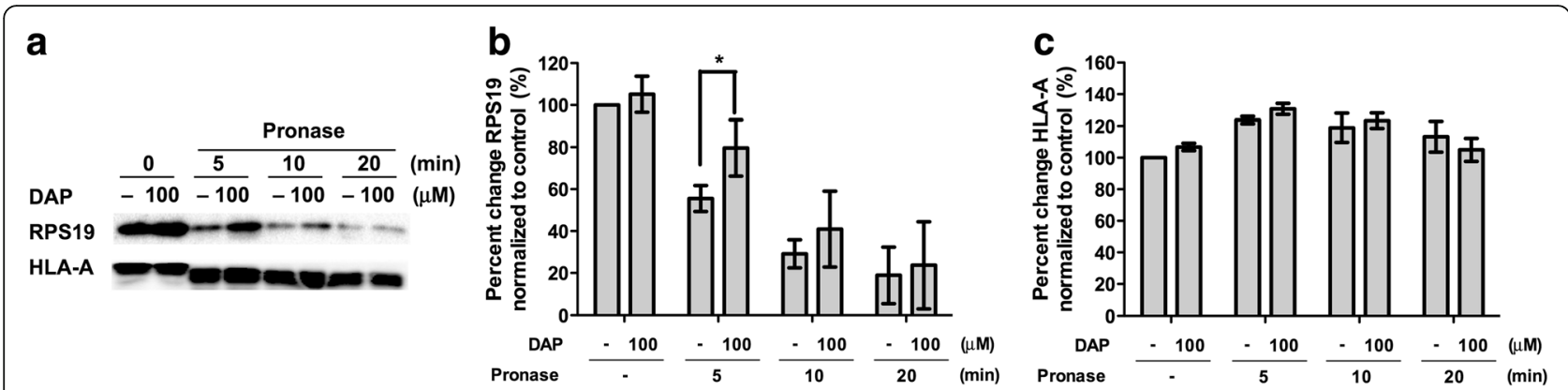

Fig. 5 Validation of the binding of DAP to RPS19 in vitro and in vivo. a Western blotting of DARTS analysis in respect with RPS19 and HLA-A (loading control) in DAP and pronase treatment. $\mathbf{b}$ graphical representation of $\mathbf{a}$ for RPS19 run in triplicate. ${ }^{*}$ designates $p<0.05$. $\mathbf{c}$ graphical representation of a) for HLA-A run in duplicate

compared to control ( $\beta$-actin; Fig. 8b). At $80 \mathrm{nM}$ siRPS19 we observed $72 \%$ growth inhibition of MCF7 cells (Fig. 8c). This dose dependent effect on growth reduction is similar to what was observed for DAP (Additional file 1: Figure S9).

Docking of DAP to the isolated structure of human RPS19, taken from the recently released high resolution cyroEM structure of the human ribosome [23] resulted in 15 lowest energy docked structures. Four of the five lowest energy docked structures are to the same site on RPS19, at the interface between rRNA and RPS19 (Fig. 10). In these structures, several of the carboxy groups of DAP took up positions close to the phosphate residues in the rRNA that RPS19 naturally binds too.

\section{Discussion}

This is the first report of the effect of DAP against human cells and indicates that there might be a specific target for DAP in humans that could explain the observed side effects or point the way to off-label applications of DAP in human pharmacology. Bioassay of DAP against a panel of human cell lines surprisingly revealed selective growth inhibition against breast (MCF7) and colon (HCT116) cancer cell lines. It appears that the differences in RPS19 expression levels between cell lines could be one of the reasons why MCF7 and HCT116 were more sensitive to DAP. Further assessment on the expression level of RPS19 in various cell lines will be conducted in a follow-up study.

There are many methods to link small molecules with their targets that all have specific advantages and disadvantages $[20,29,30]$. One of the most attractive methods (reverse chemical proteomics) is a relatively unbiased, genome wide methodology that starts with the transcriptome, which is cloned into an amplifiable vector that then displays the entire proteome of the original cell.

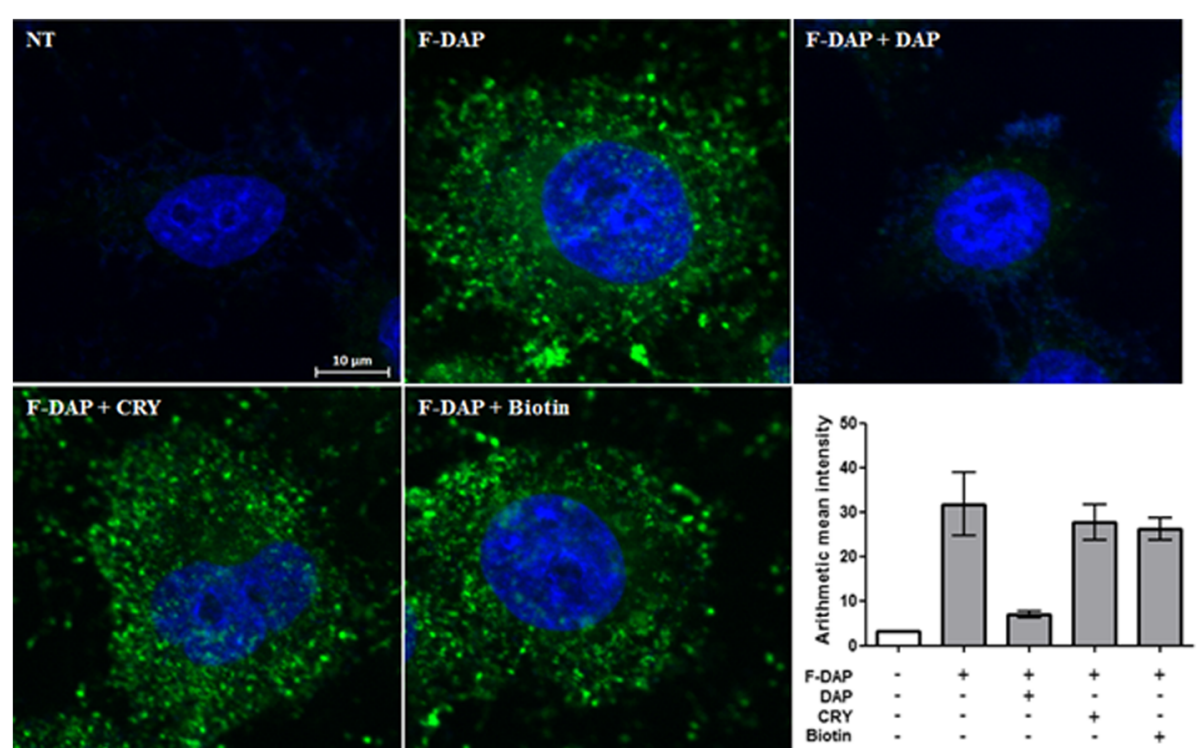

Fig. 6 In vivo competition assay between DAP and F-DAP in HeLa cells. Hoechst 33342 (blue), F-DAP (green). The graph shows mean fluorescence intensity of F-DAP 


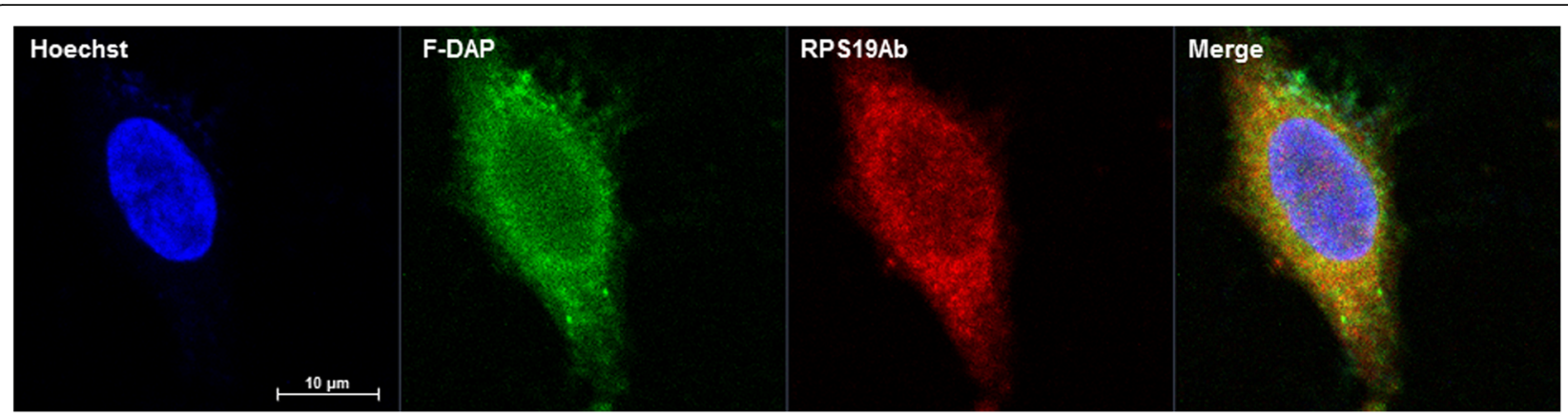

Fig. 7 Confocal images of HeLa cells. Hoechst 33342 (b/ue), F-DAP (green) and RPS19Ab (red), colocalization (orange)

Iterative biopanning (Fig. 9) can then be used to isolate the most avid binding partners of a bait molecule, regardless of how dilute the original mRNA was. Here we have chosen the underutilized T7-bacteriophage system, which has proven useful in the past for the isolation of small molecule binding proteins [31-36].

For DAP, several studies have shown which sites are suitable for derivatization without significant loss of activity and which must not be modified. From SAR studies on Orn6, it became clear that the $\gamma$-amino group is not essential for whole cell activity, but derivatization with various functional groups impacted the antibiotic activity [25]. The authors determined that the amine is required for activity but that this does not need to be a primary amine. Consequently, biotinylation was achieved through arylation of the ornithine via a reductive amination. Antibiotic activity was retained, albeit at a slightly lower level $\left(\mathrm{EC}_{50}=41 \mu \mathrm{M}\right.$ for B-DAP c.f. $5.4 \mu \mathrm{M}$ for DAP against $S$. aureus; Additional file 1: Figure S7). As $N$-alkylation of DAP is known to have no effect or enhance antibiotic activity, the observed reduction in activity is most likely due to bioavailability, with the long PEG linker and biotin hindering cell permeability.
DAP is susceptible to both alkaline and acidic degradation, giving rise to three major degradation products [37]. Under strongly alkaline conditions, ester hydrolysis between Thr4 and Kyn13 results in a ring opened product. In mildly acidic conditions ( $\mathrm{pH}=3-6)$ a two-step pathway results in the succinimido intermediate ("anhydro-DAP") at Asp9 and subsequent reversible formation of two aspartic acid isomers. At lower $\mathrm{pH}$, other degradation pathways occur. B-DAP was shown stable under the biopanning conditions $(\mathrm{pH} 7.4$ for up to $6 \mathrm{~h}$ ) for at least $12 \mathrm{~h}$ (Additional file 1: Figure S6).

After 9-12 rounds of biopanning of B-DAP against several cancer cDNA libraries, and one normal colon library, all pathological libraries started to converge onto dominant clones (Fig. 2). Analysis of the DNA sequences from a subset of the rescued phages (Fig. 3) clearly showed that the clones displaying the ribosomal protein S19 (RPS19) were the most abundant in most libraries. They comprised 11 out of 23 random plaques selected from the colon tumor library, 8 out of 23 from the liver tumor library, 7 out of 23 from the lung tumor library, and 5 out of 23 from the breast tumor library (Table 2). In conjunction with an exponential

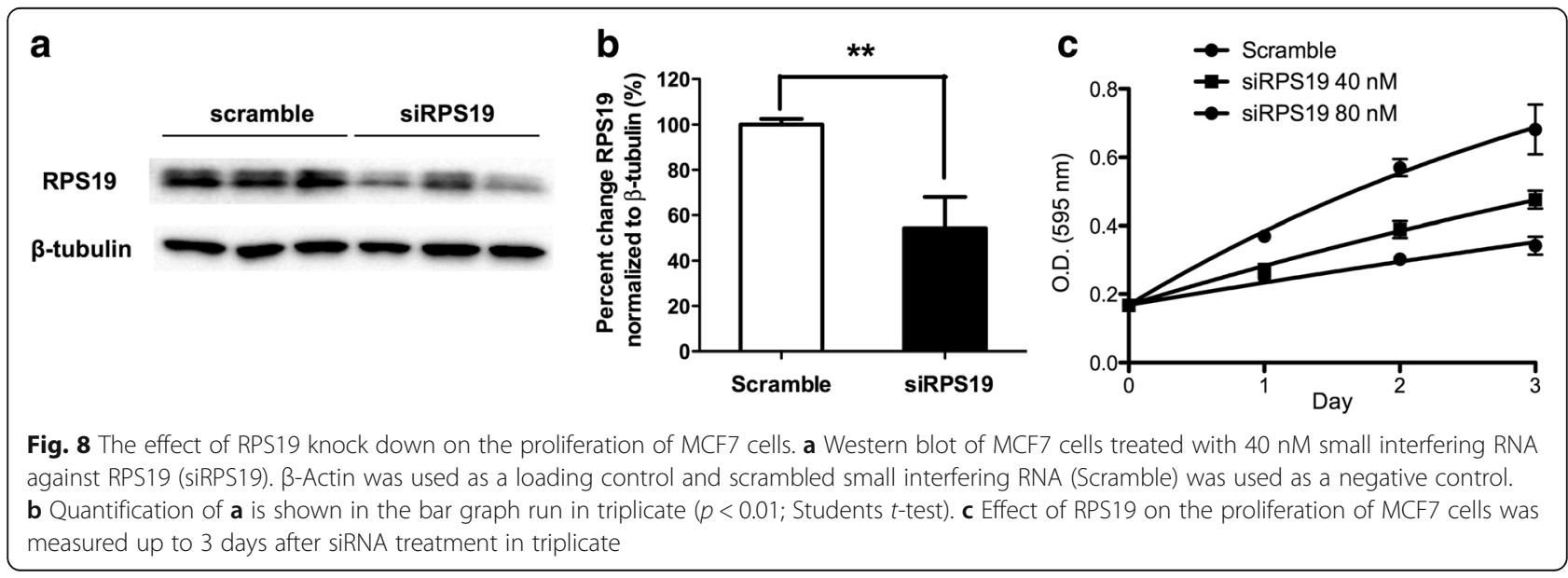




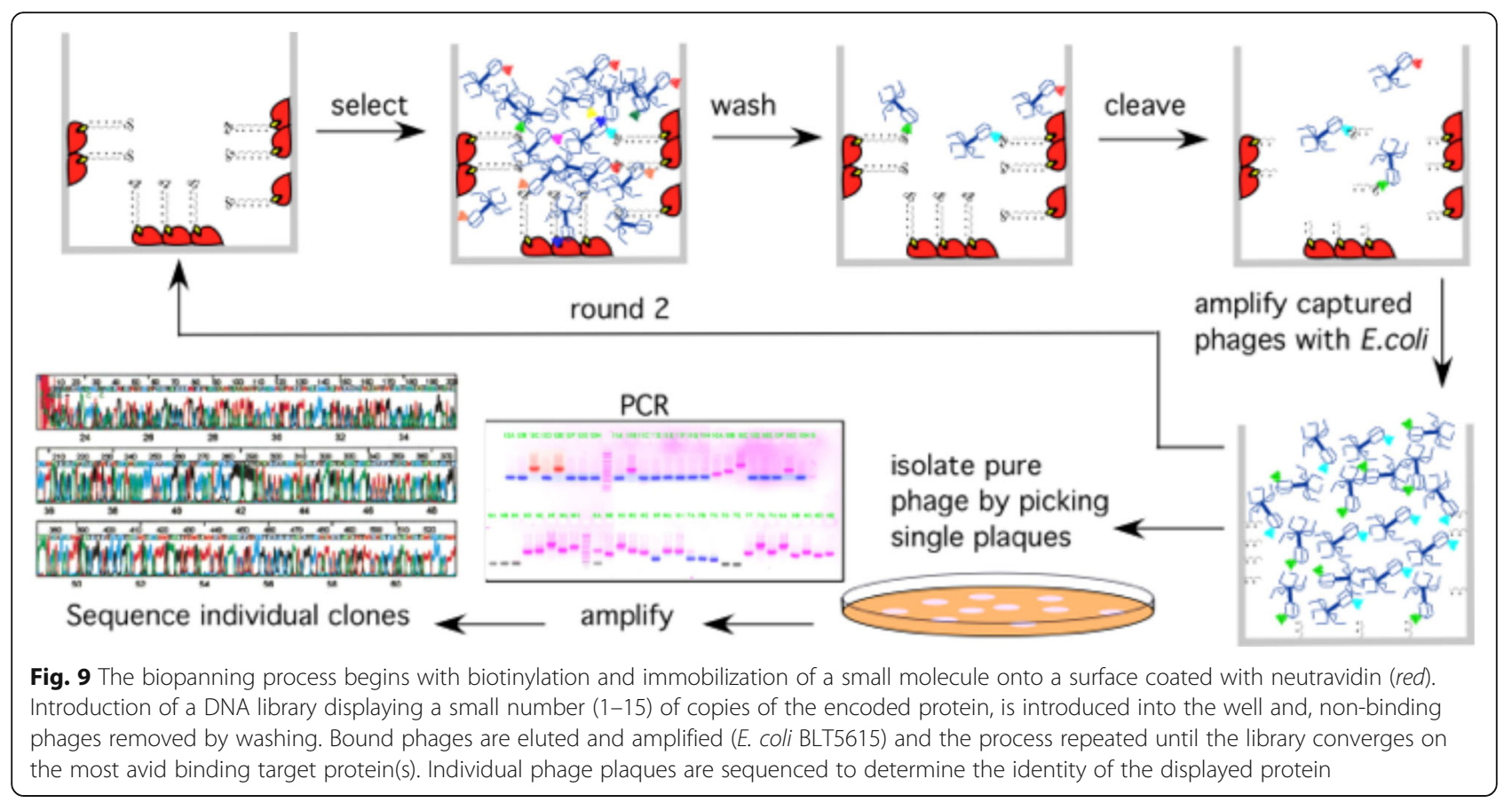

rise in titer (Additional file 1: Figure S8), this indicates a successful selection.

Alignment of all converted RPS19 proteins with the authentic human RPS19 (Additional file 1: Table S3) revealed that all the rescued clones were missing the first 21-39 amino acids with various lengths of 3'-UTR, suggesting that the binding of DAP to RPS19 did not require the first 39 amino acids. Recently the high resolution total structure of the human ribosome has been published and shows RPS19 to be located on the head of the $40 \mathrm{~S}$ subunit, extending well into the functional center of the $40 \mathrm{~S}$ subunit [23]. The protein is exposed (Fig. 10) and the binding of DAP could interfere with protein synthesis.

The RPS19 protein is a component of the $40 \mathrm{~S}$ ribosomal subunit and belongs to a family of ribosomal proteins restricted to eukaryotes (and archaea). There is no homologue of RPS19 in bacteria. It is essential for yeast viability and for early stages of development in mice [38, 39]. Disruption as well as point mutations of

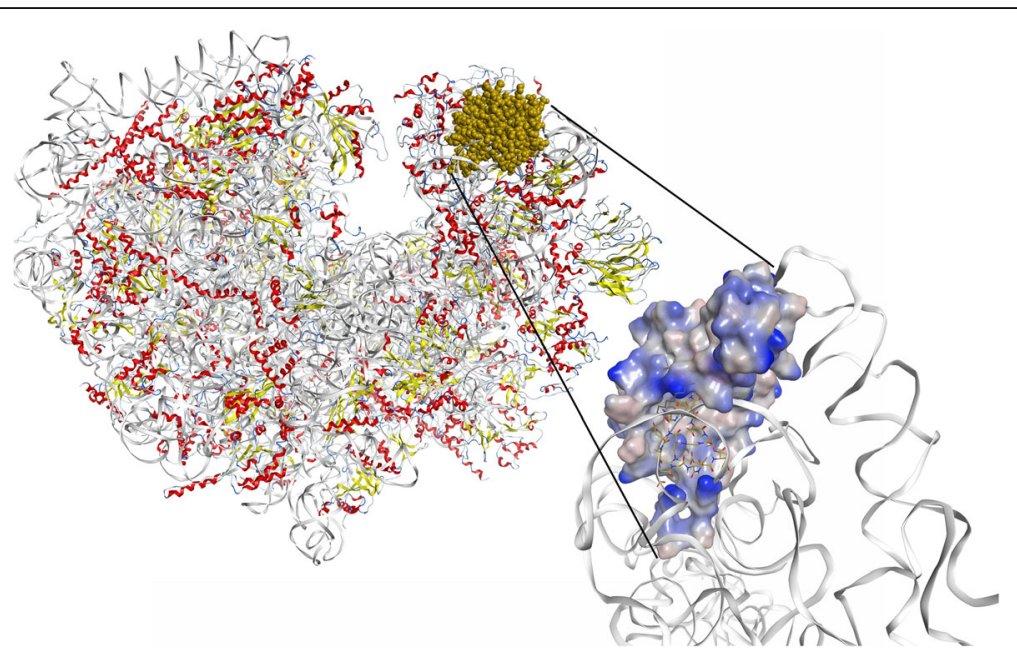

Fig. 10 CryoEM structure of the human ribosome (image of PDB ID 5T2C [36]) rendered in MOE2016. RPS19 is shown in gold. The inset shows the lowest energy DAP conformation docked to free RPS19. The solvent accessible surface is colored by hydrophocity (blue is hydrophobic, pink is hydrophilic). rRNA is indicated as a white ribbon shows that DAP can bind to the RPS19-rRNA interface 
the RPS19 gene in yeast and human cells affect maturation of the pre-ribosomal RNA (pre-rRNA) and blocks the production of the $40 \mathrm{~S}$ ribosomal subunits [38, 40, 41]. Knocking down RPS19 with siRNA leads to dramatic growth inhibition (Fig. 8), but not death of MCF7 cells in culture. Mutations of RPS19, as well as of two other ribosomal proteins, RPS24 and RPS17, have been linked to the rare congenital disease Diamond-Blackfan Anemia [41-45]. RPS19 may also have extra-ribosomal functions. For example, Kondoh et al. [46] reported higher expression levels of RPS19 in certain colon cancer cell lines, compared to normal colon tissue, which increased concomitantly with tumor progression.

From an "on-phage" binding assay, it was clear that phage expressing RPS19 had a higher affinity for B-DAP derivatized surfaces than wild-type phage (Fig. 4). However, the DARTS assay has been proven to be a much more efficient and reliable method to validate the interaction of a small molecule with its target protein in vitro $[28,29,47]$. The DARTS assay on MCF7 cell lysate showed that RPS19 is more resistant to hydrolysis in the presence of DAP, suggesting that DAP binds directly to RPS19 (Fig. 5a, b). HLA-A, an MHC class I protein, was used as an internal control. The band for HLA-A (Fig. 5a) was down-shifted, indicating a facile cleavage site in the protein but the remaining fragment was quite resistant to pronase (Fig. $5 \mathrm{c}$ ).

Staining of fixed HeLa cells with F-DAP and RPS19Ab (Fig. 6) showed a general diffuse staining of the cytoplasm that colocalized by $80 \%$. However, antibody staining requires permeabilization of the cells with detergent, which was found to disrupt F-DAP staining. Much clearer staining is obtained with F-DAP alone (Fig. 6), which was found to be freely cell permeable and stained structures inside the cells. Small molecule specific staining was confirmed by using DAP pretreatment, which effectively prevented F-DAP binding. As controls, cryptopleurine (CRY), which is known to bind the $40 \mathrm{~S}$ subunit of the ribosome [48], did not disrupt cellular staining by F-DAP. The observed staining is consistent with ribosomes in HeLa cells [49].

In the presence of a mixture of siRNAs against RPS19, cell proliferation was suppressed. It can be inferred the binding of DAP to RPS19 and knocking down RPS19 have the same general outcome on cancer cell proliferation. Molecular modelling (Fig. 10) suggested that DAP could bind to the rRNA interface with RPS19. In so doing it might interfere with incorporation of RPS19 into the ribosome and could explain why knocking down RPS19 and DAP treatment had the same qualitative outcome for cancer cells. Taken together, these data suggest that DAP could be inhibiting the cellular function of RPS19 and that RPS19 is a viable drug target for further drug development.

\section{Conclusion}

In conclusion, a genome wide, unbiased reverse chemical proteomics screen of DAP binding protein(s) in several human cancer cells identified RPS19 as a biophysically and biologically relevant target protein of DAP in humans. The interaction of DAP with RPS19 was validated using an on-phage binding assay, a label-free DARTS assay and colocalization of F-DAP with RPS19Ab. This is the first report that DAP may have selective anticancer activity and its associated human target, RPS19, could be a promising drug target protein. Further studies on the exact binding site of DAP and of the anticancer activity of DAP are warranted and may allow off-label applications of this last resort antibiotic in the field of cancer therapeutics.

\section{Additional file}

Additional file 1: Supplementary data (synthetic routes, ${ }^{1} \mathrm{H}$ NMR and MS/MS spectra of reported compounds, supplementary figures and tables) associated with this article can be found, in the online version, at http://[...]. (PDF 2959 kb)

\section{Abbreviations \\ BA: benzylaldehyde; B-DAP: biotinylated daptomycin; B-PROP: biotinylated propylamine; CRY: cryptopleurine; DAP: daptomycin; DARTS: drug affinity responsive target stability; F-DAP: fluorescent daptomycin; RPS19: ribosomal protein S19; RPS19Ab: Antibody against ribosomal protein S19; siRPS19: siRNA against RPS19; TEG: triethyleneglycol}

\section{Acknowledgements}

Not applicable.

\section{Funding}

This work was supported by ARC grant DP130103281 to P. K. and H. J. K., NRF grant 2015K1A1A2028365, 2015M3A9C4076321 to H. J. K.

\section{Availability of data and materials}

Data sharing is not applicable to this article as no datasets were generated or analysed during the current study. The following materials are available from the corresponding author (P.K.) 1. Pure T7 phage displaying RPS19, 2. Fluorescently labeled daptomycin (F-DAP).

\section{Authors' contributions}

MPG performed the syntheses, reverse chemical proteomics, on-phage binding assay, analyzed the data and wrote the first draft of the paper. SC performed cell viability assays, DARTS assay, fluorescent staining, analyzed the data and contributed to manuscript preparation. PK and HJK were responsible for the design and management of the project, analysis of the data and writing of the paper. All authors edited and approved the final manuscript.

\section{Competing interest}

The authors declare no competing interests but wish to have it known that two of them (P.K. and H.J. K) are on the editorial board of Proteome Science.

Consent for publication

Not applicable.

Ethics approval and consent to participate Not applicable.

\section{Publisher's Note}

Springer Nature remains neutral with regard to jurisdictional claims in published maps and institutional affiliations. 


\section{Author details}

Department of Chemistry and Biomolecular Sciences, Macquarie University, Sydney, NSW 2109, Australia. ${ }^{2}$ Department of Biotechnology, Yonsei University, 50 Yonsei-ro, Seodaemun-gu, Seoul 120-749, South Korea. ${ }^{3}$ Present address: School of Medical Sciences (Pharmacology), The University of Sydney, Sydney, NSW 2006, Australia.

\section{Received: 27 February 2017 Accepted: 15 June 2017}

\section{Published online: 01 July 2017}

\section{References}

1. Debono M, Barnhart M, Carrell C, Hoffmann J, Occolowitz J, Abbott B, Fukuda D, Hamill R, Biemann K, Herlihy W. A21978C, a complex of new acidic peptide antibiotics: isolation, chemistry, and mass spectral structure elucidation. J Antibiot. 1987:40:761-77.

2. Sauermann R, Rothenburger M, Graninger W, Joukhadar C. Daptomycin: a review 4 years after first approval. Pharmacology. 2008;81:79.

3. Müller A, Wenzel M, Strahl H, Grein F, Saaki TNV, Kohl B, Siersma T, Bandow JE, Sahl H-G, Schneider T, Hamoen LW. Daptomycin inhibits cell envelope synthesis by interfering with fluid membrane microdomains. Proc Natl Acad Sci. 2016;113:E7077-86

4. Laganas V, Alder J, Silverman JA. In Vitro Bactericidal Activities of Daptomycin against Staphylococcus aureus and Enterococcus faecalis Are Not Mediated by Inhibition of Lipoteichoic Acid Biosynthesis. Antimicrob Agents Chemother. 2003;47:2682-4.

5. Jung D, Rozek A, Okon M, Hancock REW. Structural Transitions as Determinants of the Action of the Calcium-Dependent Antibiotic Daptomycin. Chem Biol. 2004;11:949-57.

6. Muraih JK, Pearson A, Silverman J, Palmer M. Oligomerization of daptomycin on membranes. Biochimica et Biophysica Acta. 1808;2011:1154-60.

7. Boaretti M, Canepari P. Identification of Daptomycin-binding proteins in the membrane of Enterococcus-Hirae. Antimicrob Agents Chemother. 1995:39:2068-72.

8. Boaretti M, Canepari P, del Mar Lleo M, Satta G. The activity of daptomycin on Enterococcus faecium protoplasts: indirect evidence supporting a novel mode of action on lipoteichoic acid synthesis. J Antimicrob Chemother. 1993;31:227-35.

9. Canepari P, Boaretti M, del Mar Lleo M, Satta G. Lipoteichoic acid as a new target for activity of antibiotics: mode of action of daptomycin (LY146032). Antimicrob Agents Chemother. 1990;34:1220-6.

10. Muthaiyan A, Silverman JA, Jayaswal RK, Wilkinson BJ. Transcriptional Profiling Reveals that Daptomycin Induces the Staphylococcus aureus Cell Wall Stress Stimulon and Genes Responsive to Membrane Depolarization. Antimicrob Agents Chemother. 2008:52:980-90.

11. Lenarcic R, Halbedel S, Visser L, Shaw M, Wu LJ, Errington J, Marenduzzo D, Hamoen LW. Localisation of DivVA by targeting to negatively curved membranes. EMBO J. 2009;28:2272-82.

12. Ramamurthi KS, Losick R. Negative membrane curvature as a cue for subcellular localization of a bacterial protein. Proc Natl Acad Sci. 2009:106:13541-5.

13. Fenton C, Keating GM, Curran MP. Daptomycin. Drugs. 2004;64:445-55

14. Tally FP, Zeckel M, Wasilewski MM, Carini C, Berman CL, Drusano GL, Oleson Jr FB. Daptomycin: a novel agent for Gram-positive infections. Expert Opin Investig Drugs. 1999:8:1223-38.

15. Echevarria K, Datta P, Cadena J, Lewis JS. Severe myopathy and possible hepatotoxicity related to daptomycin. J Antimicrob Chemother. 2005:55:599-600.

16. Kostrominova T, Coleman S, Oleson F, Faulkner J, Larkin L. Effect of daptomycin on primary rat muscle cell cultures in vitro. In Vitro Cell Dev Biol Anim. 2010;46:613-8.

17. Paolini GV, Shapland RHB, Van Hoorn WP, Mason JS, Hopkins AL. Global mapping of pharmacological space. Nat Biotechnol. 2006;24:805-15.

18. Anighoro A, Bajorath J, Rastelli G. Polypharmacology: Challenges and Opportunities in Drug Discovery. J Med Chem. 2014;57:7874-87.

19. Overington JP, Al-Lazikani B, Hopkins AL. How many drug targets are there? Nat Rev Drug Discov. 2006:5:993-6.

20. Karuso P. Modern Methods for the Isolation of Natural Product Receptors. In: Mander L, Lui H-W, editors. Comprehensive Natural Products Chemistry II. Volume 9. Oxford: Elsevier; 2010. p. 513-67.

21. Novagen. T7Select Manual. In: User Protocol TB178. Rev. D 0311JN edition. pp. 1-24. USA; 2011:1-24
22. Kim D, Hwang HY, Kim JY, Lee JY, Yoo JS, Marko-Varga G, Kwon HJ. FK506, an immunosuppressive drug, induces autophagy by binding to the $\mathrm{V}$ ATPase catalytic subunit A in neuronal cells. J Proteome Res. 2017;16:55.

23. Zhang X, Lai M, Chang W, Yu I, Ding K, Mrazek J, Ng HL, Yang OO, Maslov DA, Zhou ZH. Structures and stabilization of kinetoplastid-specific split rRNAs revealed by comparing leishmanial and human ribosomes. Nat Commun. 2016;7:13223.

24. Ball L-J, Goult CM, Donarski JA, Micklefield J, Ramesh V. NMR structure determination and calcium binding effects of lipopeptide antibiotic daptomycin. Org Biomol Chem. 2004;2:8.

25. Siedlecki J, Hill J, Parr I, Yu X, Morytko M, Zhang Y, Silverman J, Controneo N, Laganas V, Li T. Array synthesis of novel lipodepsipeptide. Bioorg Med Chem Lett. 2003:13:4245-9.

26. Meldal M, Tornøe CW. Cu-catalyzed azide-alkyne cycloaddition. Chem Rev. 2008:108:2952-3015.

27. Mock DM, Lankford GL, Cazin Jr J. Biotin and biotin analogs in human urine: biotin accounts for only half of the total. J Nutr. 1993:123:1844-51.

28. Lomenick B, Hao R, Jonai N, Chin RM, Aghajan M, Warburton S, Wang J, Wu RP Gomez F, Loo JA, et al. Target identification using drug affinity responsive target stability (DARTS). Proc Natl Acad Sci. 2009;106:21984-9.

29. Chang J, Kim Y, Kwon HJ. Advances in identification and validation of protein targets of natural products without chemical modification. Nat Prod Rep. 2016:33:719-30.

30. Piggott AM, Karuso P. Quality, not quantity: The role of natural products and chemical proteomics in modern drug discovery. Comb Chem High Throughput Screen. 2004;7:607-30.

31. Jung HJ, Shim JS, Lee J, Song YM, Park KC, Choi SH, Kim ND, Yoon JH, Mungai PT, Schumacker PT, Kwon HJ. Terpestacin Inhibits Tumor Angiogenesis by Targeting UQCRB of Mitochondrial Complex III and Suppressing Hypoxia-induced Reactive Oxygen Species Production and Cellular Oxygen Sensing. J Biol Chem. 2010;285:11584-95.

32. Kim NH, Pham NB, Quinn RJ, Shim JS, Cho H, Cho SM, Park SW, Kim JH, Seok $\mathrm{SH}$, Oh J-W, Kwon HJ. The small molecule R-(-)- $\beta$-O-methylsynephrine binds to nucleoporin 153 kDa and inhibits angiogenesis. Int J Biol Sci. 2015:11:1088-99.

33. Piggott AM, Karuso P. Identifying the cellular targets of natural products using T7 phage display. Nat Prod Rep. 2016:33:626-36.

34. Shim JS, Lee J, Park H-J, Park S-J, Kwon HJ. A New Curcumin Derivative, HBC, Interferes with the Cell Cycle Progression of Colon Cancer Cells via Antagonization of the Ca2+/Calmodulin Function. Chem Biol. 2004;11:1455-63.

35. Piggott AM, Karuso P. Rapid identification of a protein binding partner for the marine natural product kahalalide $\mathrm{F}$ by using reverse chemical proteomics. ChemBioChem. 2008;9:524-30.

36. Piggott AM, Kriegel AM, Willows RD, Karuso P. Rapid isolation of novel FK506 binding proteins from multiple organisms using gDNA and CDNA T7 phage display. Bioorg Med Chem Lett. 2009;17:6841-50.

37. Muangsiri W, Kearney W, Teesch L, Kirsch L. Studies on the reactions between daptomycin and glyceraldehyde. Int J Pharm. 2005:289:133-50.

38. Léger-Silvestre I, Caffrey JM, Dawaliby R, Alvarez-Arias DA, Gas N, Bertolone SJ, Gleizes P-E, Ellis SR. Specific Role for Yeast Homologs of the Diamond Blackfan Anemia-associated Rps19 Protein in Ribosome Synthesis. J Biol Chem. 2005:280:38177-85.

39. Matsson H, Davey EJ, Draptchinskaia N, Hamaguchi I, Ooka A, Leveen P, Forsberg E, Karlsson S, Dahl N. Targeted Disruption of the Ribosomal Protein S19 Gene Is Lethal Prior to Implantation. Mol Cell Biol. 2004;24:4032-7.

40. Choesmel V, Bacqueville D, Rouquette J, Noaillac-Depeyre J, Fribourg S, Cretien A, Leblanc T, Tchernia G, Da Costa L, Gleizes P-E. Impaired ribosome biogenesis in Diamond-Blackfan anemia. Blood. 2007;109:1275-83.

41. Flygare J, Aspesi A, Bailey JC, Miyake K, Caffrey JM, Karlsson S, Ellis SR. Human RPS19, the gene mutated in Diamond-Blackfan anemia, encodes a ribosomal protein required for the maturation of $40 \mathrm{~S}$ ribosomal subunits. Blood. 2007;109:980-6.

42. Idol RA, Robledo S, Du H-Y, Crimmins DL, Wilson DB, Ladenson JH, Bessler M, Mason PJ. Cells depleted for RPS19, a protein associated with Diamond Blackfan Anemia, show defects in $18 \mathrm{~S}$ ribosomal RNA synthesis and small ribosomal subunit production. Blood Cells Mol Dis. 2007;39:35-43.

43. Gazda HT, Grabowska A, Merida-Long LB, Latawiec E, Schneider HE, Lipton JM, Vlachos A, Atsidaftos E, Ball SE, Orfali KA, et al. Ribosomal Protein S24 Gene Is Mutated in Diamond-Blackfan Anemia. Am J Hum Genet. 2006:79:1110-8.

44. Cmejla R, Cmejlova J, Handrkova H, Petrak J, Pospisilova D. Ribosomal protein $\mathrm{S} 17$ gene (RPS17) is mutated in Diamond-Blackfan anemia. Hum Mutat. 2007;28:1178-82. 
45. Ellis SR, Massey AT. Diamond Blackfan anemia: A paradigm for a ribosomebased disease. Med Hypotheses. 2006;66:643-8.

46. Kondoh N, Schweinfest CW, Henderson KW, Papas TS. Differential Expression of S19 Ribosomal Protein, Laminin-Binding Protein, and Human Lymphocyte Antigen Class I Messenger RNAs Associated with Colon Carcinoma Progression and Differentiation. Cancer Res. 1992;52:791-6.

47. Kim D, Hwang HY, Kim JY, Lee JY, Yoo JS, Marko-Varga G, Kwon HJ. FK506, an Immunosuppressive Drug, Induces Autophagy by Binding to the V-ATPase Catalytic Subunit A in Neuronal Cells. J Proteome Res. 2017;16:55-64.

48. Dolz H, Vazquez D, Jimenez A. Quantitation of the specific interaction of [14a-3H]cryptopleurine with $80 \mathrm{~S}$ and $40 \mathrm{~S}$ ribosomal species from the yeast Saccharomyces cerevisiae. Biochemistry. 1982;21:3181-7.

49. Tsai Y-J, Lee H-I, Lin A. Ribosome Distribution in HeLa Cells during the Cell Cycle. PLOS ONE. 2012;7, e32820.

\section{Submit your next manuscript to BioMed Central} and we will help you at every step:

- We accept pre-submission inquiries

- Our selector tool helps you to find the most relevant journal

- We provide round the clock customer support

- Convenient online submission

- Thorough peer review

- Inclusion in PubMed and all major indexing services

- Maximum visibility for your research

Submit your manuscript at www.biomedcentral.com/submit 